\section{BMJ Paediatrics Open}

\title{
Supply of unlicensed medicines to children: semi-structured interviews with carers
}

\author{
Nicola Rachel Husain, ${ }^{1,2}$ J Graham Davies, ${ }^{1}$ Stephen Tomlin ${ }^{2}$
}

To cite: Husain NR, Davies JG, Tomlin S. Supply of unlicensed medicines to children: semistructured interviews with carers. BMJ Paediatrics Open 2017;1:e00051. doi:10.1136/ bmjpo-2017-000051

- Prepublication history for this paper is available online. To view these files please visit the journal online (http://dx.doi.org/ 10.1136/bmjpo-2017-000051)

Received 25 April 2017

Revised 4 July 2017

Accepted 5 July 2017

\section{CrossMark}

1 Institute of Pharmaceutical Science, King's College London, London, UK

${ }^{2}$ Evelina London Children's Hospital, Guy's \& St Thomas' NHS Foundation Trust, London, UK

Correspondence to Nicola Rachel Husain; nicola. husain@kcl.ac.uk

\section{ABSTRACT}

Objectives To explore the experiences of parents and carers relating to the supply of unlicensed medicines for their child after discharge from hospital.

Methods Semi-structured interviews were conducted with 15 parents and carers of children who were newly prescribed an unlicensed medicine. Interviews were conducted at least 4 weeks after the child's discharge from hospital. Qualitative thematic analysis of the data was carried out.

Results Problems were frequently encountered by parents when attempting to obtain further supplies of their child's unlicensed medicine. Problems included general practitioners (GPs) refusing to prescribe the medicine, GPs prescribing a dose or formulation that differed to what had been prescribed previously, pharmacists who were unable to source a suitable medicine, medicines that were not labelled with administration instructions and delays in obtaining the medicine. Action or intervention by the parent was often required to overcome the problems faced. The necessity of these actions or interventions, and the implication of not succeeding, frequently caused parents anxiety, frustration and dissatisfaction.

Conclusions Strategies for improving the process of medicine supply during the transition between secondary and primary care are necessary and must involve greater communication among healthcare professionals and carers. GPs and community pharmacists should have access to greater support and guidance to facilitate the safe prescribing and supply of unlicensed medicines. Parents and carers should be informed about the process to ensure understanding, create empowerment and to build relationships between them and the professionals responsible for the care of their child.

\section{INTRODUCTION}

Within paediatric care, medicines are commonly prescribed outside the terms of the medicine's marketing authorisation (termed 'off-label'). Furthermore, the use of medicines without marketing authorisation (termed 'unlicensed') is often necessitated. ${ }^{1}$ Paediatric use of unlicensed and off-label medicines is associated with a greater incidence of medication errors, adverse drug reactions and unplanned hospital admissions when compared with licensed medicines. ${ }^{2-4}$

\section{What is already known on this topic?}

'Off-label' and 'unlicensed' medicines use is associated with medication risk. GPs and community pharmacists often admit to a poor understanding of licensing regulations and the implications of supplying unlicensed or off-label medicines to children.

\section{What this study adds?}

Parents and carers experience problems when attempting to obtain unlicensed medicines for their child following discharge from hospital. Problems can occur at the prescribing and dispensing stage and are a source of concern and anxiety for parents and carers.

The increased risk of such occurrences may result from a lack of prescribing guidance for unlicensed medicines, lack of product standardisation and from dosage form manipulation. ${ }^{56}$

Treatment with unlicensed or off-label medicines is typically initiated within secondary care, with responsibility for ongoing supply adopted by the child's general practitioner (GP) and community pharmacist. This arrangement allows the child's parent or carer to obtain medicines close to home. However, previous studies have shown that taking responsibility for the use of these medicines is a source of concern for GPs and community pharmacists, many of whom admit to a poor understanding of the licensing process and the implications of supplying unlicensed or off-label medicines to children. ${ }^{7-10}$ Furthermore, a study in 2006 found that $33 \%$ of carers experienced problems when attempting to obtain unlicensed and off-label medicines for their child after being discharged from a specialist paediatric hospital. ${ }^{11}$

While it has been shown that some carers experience difficulties when attempting to obtain unlicensed medicines for their child, 


\section{How participants sought to obtain further supplies of the medicine Issues/problems encountered and how they were overcome \\ Views on the participants' experiences of the medicine supply process \\ Views of how the medicine supply process could be improved \\ Any other comments or views on the subject}

Figure 1 Topic guide for semi-structured interviews.

limited studies have described their experiences during this process. This qualitative study was therefore designed to explore the experiences of parents and carers relating to the supply of unlicensed medicines for their child after discharge from hospital.

\section{METHODS}

\section{Participant selection and recruitment}

Prescriptions for newly prescribed unlicensed medicines, for which prescribing was expected to be continued by the child's GP, were identified by pharmacy staff at the Evelina London Children's Hospital (ELCH). Participants (parents and carers) were recruited purposively using a sampling matrix that accounted for the age of the child, their inpatient/outpatient status and the clinical specialty of the indication for the unlicensed medicine. Written consent was obtained prior to the child's discharge from hospital.

\section{Data collection}

Telephone interviews with participants were conducted approximately 4 weeks after their child's discharge from hospital. A topic guide was designed, piloted and refined with input from specialist paediatric pharmacists (see figure 1). A qualitative, semi-structured format was used to allow participants to describe their own experiences and to permit the disclosure of thoughts and ideas that were not anticipated by the researcher. Interviews were audiorecorded and transcribed verbatim.

\section{Qualitative data analysis}

Text blocks from the transcripts were open coded into categories and subcategories using an inductive thematic analysis approach. Categories and subcategories were iteratively refined until a robust analytical framework was developed. The finalised framework was reapplied digitally to all transcripts using NVivo version 10 qualitative data analysis software (QSR International , 2012). The coded data were reviewed and interpreted in the context of individual interviews and the complete data set. Commonalities and themes were identified and explored.

\section{RESULTS}

Twenty-three parents consented to take part. Of these, eight were not interviewed for the following reasons: medicine was discontinued (four patients); participant was
Table 1 Medicines prescribed to the children

\begin{tabular}{ll} 
Unlicensed medicines & $\begin{array}{l}\text { Licensed medicines } \\
\text { prescribed off-label }\end{array}$ \\
\hline Beclometasone dipropionate & Carbamazepine liquid \\
$0.0025 \%$ ointment & Clobazam liquid \\
Clonidine liquid & Ethosuximide liquid \\
Colecalciferol liquid & Furosemide liquid \\
Glycine sachets & Levetiracetam liquid \\
Glycopyrrolate tablet & Levocarnitine liquid \\
Lisinopril liquid & Propranolol liquid \\
Melatonin liquid & Sodium valproate liquid \\
Midazolam buccal solution & Vigabatrin sachets \\
Omeprazole liquid & \\
Sodium benzoate liquid & \\
Sodium chloride oral solution & \\
Spironolactone liquid & \\
Tacrolimus liquid & \\
\hline
\end{tabular}

not contactable (three patients) and hospital discharge was delayed beyond the period of data collection (one patient). Unlicensed medicines were prescribed for seven children in the outpatient setting and for eight children who were discharged from inpatient wards. Their age ranged from 2 weeks to 15 years (median age 3 years). Unlicensed medicines were prescribed for the following clinical specialties: cardiology (four patients), dermatology (three patients), endocrinology (three patients), neurology (three patients) metabolic (two patients) and renal (two patients). The unlicensed medicines prescribed were: beclometasone dipropionate $0.0025 \%$ ointment, clonidine liquid, colecalciferol liquid and spironolactone liquid (three patients each); lisinopril liquid and omeprazole liquid (two patients each) and glycine sachets, glycopyrrolate tablets, melatonin liquid, midazolam buccal solution, sodium benzoate liquid, sodium chloride oral solution and tacrolimus liquid (one patient each). The unlicensed and off-label medicines that were prescribed are listed in table 1.

The finalised analytical framework contained three categories and 21 subcategories, which are shown in table 2.

\section{Problems and concerns}

The first step to obtaining further supplies for all participants was making contact with GP surgery staff. In most cases, communication with surgery staff was reported as good, although some difficulties were faced:

\footnotetext{
P7: "What we've found - and we found it again this time - when he has his meds changed, the first time we had to get the prescription written up, it's really frustrating and becomes a bit of a pain if it is not written up right... So like this time... his prescription got written up but his GP didn't put it on repeat... Trying to explain to the receptionist... and they say 'well, the GP has not put it on repeat', and you say 'he's just come out of hospital'... again, it's sometimes like you are having to battle."
} 


\begin{tabular}{|c|c|}
\hline Category & Subcategory \\
\hline $\begin{array}{l}\text { Problems and } \\
\text { concerns }\end{array}$ & $\begin{array}{l}\text { GP unwilling to prescribe or other } \\
\text { prescribing issues } \\
\text { Communication difficulties with GP } \\
\text { surgery staff } \\
\text { Wrong product, formulation or strength } \\
\text { prescribed } \\
\text { Insufficient quantity prescribed } \\
\text { Communication difficulties with pharmacy } \\
\text { staff } \\
\text { Delay in obtaining medicine from } \\
\text { pharmacy } \\
\text { Medicine not labelled with directions } \\
\text { Lack of information about the medicine }\end{array}$ \\
\hline $\begin{array}{l}\text { Actions and } \\
\text { strategies }\end{array}$ & $\begin{array}{l}\text { Additional interaction with GP surgery staff } \\
\text { Additional interaction with pharmacy staff } \\
\text { Requested assistance from other } \\
\text { healthcare professionals } \\
\text { Requested larger quantity to be } \\
\text { prescribed } \\
\text { Asked pharmacy staff to keep medicine } \\
\text { as stock } \\
\text { Used one regular pharmacy } \\
\text { Used multiple pharmacies } \\
\text { Obtained medicine from local or specialist } \\
\text { hospital } \\
\text { Planning and organising the process } \\
\text { Sought information about the medicine }\end{array}$ \\
\hline $\begin{array}{l}\text { Views and } \\
\text { perceptions }\end{array}$ & $\begin{array}{l}\text { Perceptions of GP surgery and pharmacy } \\
\text { staff } \\
\text { Perceptions and understanding of the } \\
\text { medicine supply process } \\
\text { Views on how the medicine supply } \\
\text { process should be delivered or improved }\end{array}$ \\
\hline
\end{tabular}

GP, general practitioner.

Most participants reported that a consultation with the GP had not been required. This was generally acceptable to participants, although one (P6), whose child had been in hospital since birth, believed a medical review would have provided reassurance:

P6: "We haven't seen the GP yet, they didn't want to see us... So the GP's never seen [my son]... But then we've got our 6-weekly check next week, so that's where our confidence, I think, will get a bit better."

A number of participants reported that their child's GP was unwilling to prescribe the new unlicensed medicine. Perceived reasons for this were 'cost' (colecalciferol liquid; beclometasone dipropionate $0.0025 \%$ ointment) and that the GP was 'not allowed' to prescribe it (clonidine liquid; chloral hydrate liquid). In three cases, supplies from the hospital had been exhausted and parents had been unable to obtain a new supply.

A frequent complaint concerned the quantity of medicine that the GP would prescribe. Concerns about receiving small quantities focused on the frequency with which prescriptions would need to be obtained to replenish supplies, a desire to keep additional supplies at home in case of loss or spillage and to provide supplies to parents who lived separately but shared childcare responsibilities.

All participants were aware that the unlicensed medicine was unlikely to be immediately available at local pharmacy. However, participants expressed dissatisfaction at the time it took for the medicine to be procured, especially when they were not informed by the pharmacy staff about the anticipated waiting time. The time needed to procure unlicensed medicines was a worry for participants:

\section{P12: "What happens if I drop the bottle, for instance? I'm absolutely terrified I won't be able to get any more quick enough."}

For several participants, it transpired after receiving the medicine that the formulation or strength prescribed by the GP differed to the product prescribed at ELCH. Some reported receiving a liquid medicine that was a different strength to that issued at the hospital; all reported that the change had not been communicated to them although most had identified that the resulting dosage volume needed to change. In addition to the discrepancies identified by participants, one prescribing error was identified by the interviewer: a change in formulation made by the GP (from liquid to capsules) resulted in a 10 -fold dose decrease of colecalciferol. Several participants reported that the new medicine was not labelled with administration instructions.

\section{Actions and strategies}

Participants reported a variety of strategies for overcoming the issues they had encountered. Several participants who faced problems obtaining a prescription enlisted the help of other healthcare professionals-including health visitors (community public health nurses or midwives), community nurses, hospital nurse specialists and other GPs- to liaise with the child's GP on their behalf. The perception expressed was that another healthcare professional would have more influence over the GP:

P2: "This morning I contacted my health visitor - because they seem to be very good at passing on messages and making people do what they are supposed to do - so at some point today she's trying to get the doctor to do the prescription."

In response to the time delay between requesting a prescription and obtaining the medicine, nearly all participants believed that planning and organisation were critical to ensure continuity of supply. This was particularly evident for participants who had prior experience of obtaining unlicensed medicines.

P7: "We've been through this now for sixyears - we know what's going to happen and we pre-empt things. Luckily, when we get his prescriptions - due to things like delays or having to get medicines ordered or anything like that - we 
always do it with at least a week's worth of medicines still to go."

Participants commented that the need to plan and organise prescriptions and medicine supplies caused them 'worry' and 'stress'. Several participants kept 'spare' supplies in case of loss or spillage, although the short shelflife of some medicines limited the effectiveness of this approach. Another strategy to safeguard against running out of medicines involved asking the GP to prescribe a greater quantity on each occasion. Other participants asked their pharmacy to stock the unlicensed medicine so that it would be readily available when they presented a prescription; however, the responses received were variable:

P12: "[The pharmacist] said 'we don't order it for anybody else, so we don't ever keep any as stock, but what I will do is... I'll order a spare, so we will always have one in the pharmacy'. Which was lovely.'

P6: "[The pharmacist] said no, because it costs...I think they said $£ 50$ a bottle. They wouldn't keep any in stock, which is obviously a concern.'

Five participants had contacted ELCH or their local hospital to request supplies of the unlicensed medicine after failing to obtain it locally. Others reported needing to visit several pharmacies before finding one able to supply the medicine. The possibility of not obtaining the medicine in time caused participants to experience 'panic'and 'frustration' and to feel 'afraid'.

\section{Views and perceptions}

A common view expressed by participants was that the hospital consultant was the singular 'prescriber' of the medicine and the GP's role in the supply process was to furnish the participant with a prescription to enable them to obtain further supplies from a pharmacy. One participant (P6) thought that the GP was '...just signing stuff... without really knowing what he's signing'. They believed that the GP '...is trumped by the consultants'. Another participant described their understanding of the process:

P1: "It's prescribed at the Evelina, but we need to go to the GP to get a prescription... It must come from the surgery but it doesn't really come from them, it comes from [Dr at ELCH], so it is a bit confusing."

Participants who expressed views about their interaction with pharmacy staff focused mostly on communication. Some expressed frustration when questioned by pharmacy staff:

P7: "When... they start asking the same questions again it gets a bit frustrating. But it's one of those things, I'd rather be questioned than not questioned to ensure that there are people looking out for [my son]'s safety."

Others believed that greater interaction would have provided reassurance:
P6: "[They said] nothing - they just handed them over. I think it's just that interaction... I just went up and picked them up, there was no 'are you happy with them?' They just gave me the bag. It was as if you went and bought some Anadin from behind the counter."

\section{DISCUSSION}

This study demonstrates that the current approach to supplying unlicensed medicines to children has a number of major failings relating to both the prescribing and dispensing stages. Participants encountered GPs who were either unwilling to prescribe for their child or prescribed a dose, formulation or strength of medicine that differed to what had been issued previously. Participants faced long waiting times for medicines to be procured and received minimal limited information from pharmacy staff. Many participants expressed dissatisfaction with their experience; the primary cause of this was the uncertainty of knowing whether a continued supply of the medicine was assured and therefore whether their child would receive the medicine. These experiences challenged the relationships between participants and their child's healthcare professionals.

Some doses were missed as a result of difficulties faced by participants when attempting to obtain their child's unlicensed medicine. Participants also reported that changes were made to the medicine's strength or formulation. While a change in product does not necessarily compromise care, unlicensed medicines are not subject to the same regulations as licensed medicines and so bioavailability-and therefore clinical effect-may vary between products. Changes to a product's formulation or strength and omitted dosing instructions can also result in inadvertent administration errors unless such changes are explicitly explained to the parent.

Participants expected their child's GP to prescribe, and their local pharmacy to dispense, the medicine initiated by ELCH. The participants' expectations are logical and understandable but may not be realistic within the current medicine supply system: it cannot be presumed that a GP will agree to continue a medicine recommended by another physician and pharmacists may lack the clinical or pharmaceutical expertise to source or dispense unlicensed medicines. Indeed, some children's hospitals have elected to provide long-term supplies of unlicensed medicines to patients and are reimbursed by commissioners for delivering this service. ${ }^{12}$

Many participants expressed feelings of frustration, stress and anxiety from their experiences of negotiating the transition of medicine supply between hospital and primary care. For many, a successful outcome depended on perseverance and organisation. Some went to great lengths to ensure doses were not omitted: making an emergency trip to hospital to collect a medicine, for example. 
Some issues identified in this study may be prevented through improvements in communication between hospital healthcare professionals and those within primary care. Earlier dialogue would ensure GPs have the necessary information to prescribe and monitor the patient safely, or if they feel unable to assume the prescribing role, to inform the child's consultant prior to the child's discharge from secondary care. Furthermore, greater contact between hospital and community pharmacists may help those in community to source suitable products and prevent dispensing or labelling issues. GPs and community pharmacists who are unable or unwilling to assume responsibility should have a duty to assist the parent to liaise with hospital staff to facilitate supply from an alternative source.

For parents and carers to be satisfied and engaged with the process of medicine supply, it is vital that they are informed about the process and understand the roles of GPs and community pharmacists. Throughout the transition from hospital to primary care, staff should ensure that parental expectations concerning waiting times and quantity of supply are realistic and should highlight the common problems associated with unlicensed medicines, such as the implication of strength changes of liquid medicines.

This study highlights the nature and severity of problems that parents and carers encountered when attempting to obtain unlicensed medicines for their child following discharge from hospital. Strategies for improving this process are necessary: greater dialogue between healthcare professionals is required and greater support should be provided to GPs and community pharmacists to facilitate safe supply of unlicensed medicines within primary care. Parents and carers should be engaged throughout the transition process to ensure they understand the roles of the healthcare professionals involved and what to expect when the child's care is transferred from hospital to community.

Acknowledgements The authors wish to thank the participants for sharing their experiences.

Contributors Conception or design of the work, critical revision of the article and final approval of the version to be published: all authors. Data collection, analysis and interpretation, and drafting the article: NRH.
Competing interests None declared.

Ethics approval Ethical approval was granted by the North-West National research ethics service committee on 29 April 2014 (reference 14/NW/0243).

Provenance and peer review Not commissioned; externally peer reviewed.

Open Access This is an Open Access article distributed in accordance with the Creative Commons Attribution Non Commercial (CC BY-NC 4.0) license, which permits others to distribute, remix, adapt, build upon this work non-commercially, and license their derivative works on different terms, provided the original work is properly cited and the use is non-commercial. See: http://creativecommons.org/licenses/by-nc/4.0/

(c) Article author(s) (or their employer(s) unless otherwise stated in the text of the article) 2017. All rights reserved. No commercial use is permitted unless otherwise expressly granted.

\section{REFERENCES}

1. Cuzzolin L, Atzei A, Fanos V. Off-label and unlicensed prescribing for newborns and children in different settings: a review of the literature and a consideration about drug safety. Expert Opin Drug Saf 2006;5:703-18.

2. Conroy S. Association between licence status and medication errors. Arch Dis Child 2011;96:305-6.

3. Horen B, Montastruc JL, Lapeyre-Mestre M. Adverse drug reactions and off-label drug use in paediatric outpatients. Br J Clin Pharmacol 2002;54:665-70.

4. Bellis JR, Kirkham JJ, Nunn AJ, et al. Adverse drug reactions and off-label and unlicensed medicines in children: a prospective cohort study of unplanned admissions to a paediatric hospital. $\mathrm{Br} J$ Clin Pharmacol 2014;77:545-53.

5. Mulla H, Hussain N, Tanna S, et al. Assessment of liquid captopril formulations used in children. Arch Dis Child 2011;96:293-6.

6. Richey RH, Shah UU, Peak M, et al. Manipulation of drugs to achieve the required dose is intrinsic to paediatric practice but is not supported by guidelines or evidence. BMC Pediatr 2013;13:81.

7. Mukattash T, Hawwa AF, Trew K, et al. Healthcare professional experiences and attitudes on unlicensed/off-label paediatric prescribing and paediatric clinical trials. Eur J Clin Pharmacol 2011;67:449-61.

8. Chisholm A. Exploring UK attitudes towards unlicensed medicines use: a questionnaire-based study of members of the general public and physicians. Int J Gen Med 2012;5:27-40.

9. Paediatricians' BM. And GPs' understanding of the "medicine notlicensed for use in children". Arch Dis Child 2013;98:A14-A15.

10. Venables R, Marriott J, Stirling H. Healthcare professionals' understanding of children's medicines. Int $\mathrm{J}$ Pharm Pract 2012;20:68-9.

11. Wong IC, Basra N, Yeung VW, et al. Supply problems of unlicensed and off-label medicines after discharge. Arch Dis Child 2006;91:686-8

12. Terry DRP, Sinclair AG, Ubhi H, et al. Cost benefit of hospital led supplies of unlicensed medicines for children at home. Arch Dis Child 2012;97:e15.1-e15. 